\title{
The Response of Water Level in the YuZ-5 Well, Kamchatka to the Magnitude 9.3, Sumatra-Andaman Earthquake of December 26, 2004
}

\author{
G. N. Kopylova and S. V. Boldina \\ Kamchatka Branch, Geophysical Service, Russian Academy of Sciences, \\ Petropavlovsk-Kamchatskii, 683006 Russia \\ Received December 25, 2006
}

\begin{abstract}
Forced and free oscillations of water level were recorded in the YuZ-5 well, Kamchatka due to the passage of seismic waves from the Sumatra-Andaman earthquake of December $26,2004, \mathbf{M}_{w}=9.3$, hypocentral distance $8250 \mathrm{~km}$. The greatest amplitude of water level oscillations, at least $5 \mathrm{~cm}$, was observed during the onset of seismic surface waves with a typical period of 20-50 s. The total duration of the forced and free water level oscillations was about ten hours. The available theoretical models that describe oscillations of water level in a well due to seismic waves and rapid injection of water were used to estimate the transmissivity of the aquifer. The values obtained exceed by at least two orders of magnitude the transmissivity derived from pumping test measurements. A hypothesis was proposed to explain the temporary increase in aquifer transmissivity during the passage of seismic waves by invoking disturbances in the structure of the crack-pore space and a sharp increase in aquifer rock permeability.
\end{abstract}

DOI: $10.1134 / \mathrm{S} 0742046307050041$

\section{INTRODUCTION}

Water level observations in piezometric wells include simultaneous recordings of water level and atmospheric pressure variations, and are commonly regarded as an effective tool for monitoring the state of stress and strain in the upper crust. For example, the response of water level to earth tides shows that water level observations can be used to detect small crustal strains on order $10^{-8}$ to $10^{-9}$. Special interest attaching to this kind of geophysical observations is due to the fact that the water level behavior in wells involves various changes caused by the precursory processes and occurrences of large earthquakes $[1,2]$. This points to the need for detailed studies in the seismicity-induced hydrogeodynamic processes occurring in a well-aquifer system.

Seismic waves excited by large teleseismic events may cause appreciable changes in water level observed in wells $[1,7]$. Following the $\mathbf{M}_{w}=8.8$ Alaskan earthquake of March 28, 1964, water level fluctuations were observed as far as $11000 \mathrm{~km}$ from the source. The water level variations of amplitude between a few centimeters and $4.5 \mathrm{~m}$ lasted a few hours to 24 hours $[1,8]$.

It is of interest that the response of water level to the passage of seismic waves in closely spaced wells may have substantially different amplitudes. The study of such water level variations is of interest for geophysicists, seismologists, and hydrologic geologists; first, because well-aquifer systems can be used as a kind of receiver of seismic signals and, secondly, in order to assess the properties of the aquifer, its transmissivity in the first place.

This paper describes the effects due to the passage of seismic waves excited by the December 26, 2004, Sumatra-Andaman earthquake, $\mathbf{M}_{w}=9.3$, as recorded in water level changes at the YuZ-5 well, Kamchatka. A model for the motion of the water column in a well during the development of a pore-pressure cone of depression due to the passage of seismic waves [7] was used to assess the transmissivity of the aquifer penetrated by the YuZ-5 well. The transmissivity value obtained is compared with those evaluated from tidal and barometric responses of water level, from pumping test, and from an analytical relation that describes the oscillatory behavior of water level when water is instantaneously injected into the well.

The Observations, Parameters of the Aquifer, and the Earthquake-Induced Response of Water Level

The observations at the YuZ-5 well $\left(53.169^{\circ} \mathrm{N}\right.$, $158.414^{\circ} \mathrm{E}$, depth $800 \mathrm{~m}$ ) are conducted by the Kamchatka Branch, RAS Geophysical Service using a Kedr A2 digital system manufactured by Polinom Ltd., Khabarovsk for recording water level and atmospheric pressure. The sample rate is once per $10 \mathrm{~min}$, the accuracy of water level recording is $0.1 \mathrm{~cm}$, and that of atmospheric pressure is 0.2 mbars. The water level in the well is $1 \mathrm{~m}$ below the ground surface. The geologic and hydrogeologic conditions and the well construction are described in $[2,3]$. 


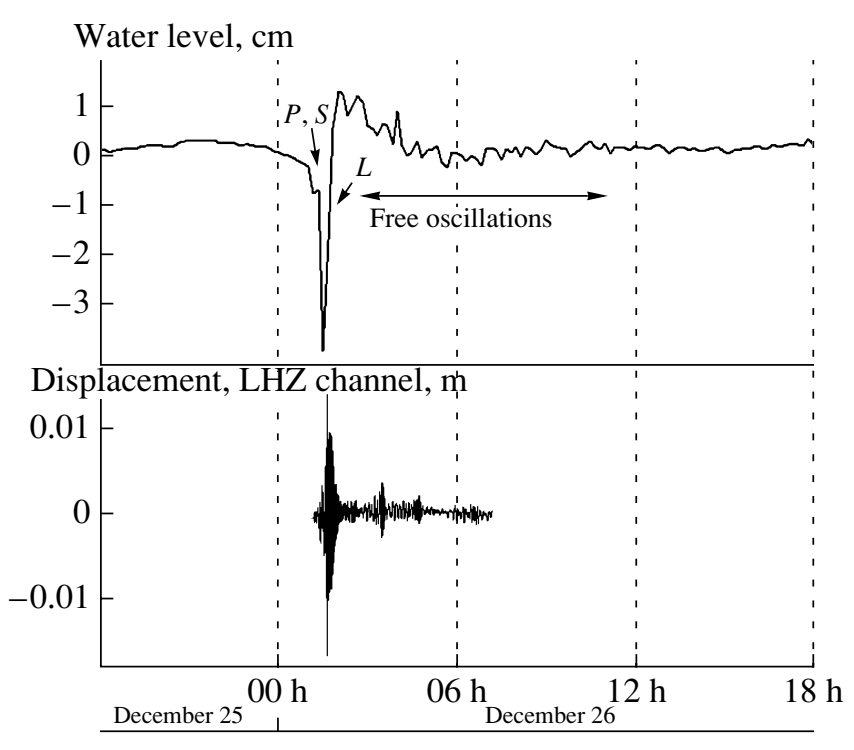

Fig. 1. Water level changes in the YuZ-5 well during the December 26, 2004, Sumatra-Andaman earthquake $\left(\mathrm{M}_{w}=\right.$ 9.3) compared with displacements recorded by the LHZ channel, Petropavlovsk seismic station. Arrows mark arrivals of $P, S$, and $L$ waves.

There is no casing in the depth range $310-800 \mathrm{~m}$ where the well screens a hydraulically connected confined aquifer in Late Cretaceous deposits consisting of alternating aleurolites and phyllites. The well has a radius of $r_{w}=0.084 \mathrm{~m}$ in this depth range, with the radius of the casing tube in the region of water level fluctuations being $r_{c}=0.123 \mathrm{~m}$. The water inflow zones of total thickness $100 \mathrm{~m}$ are confined to cracked aleurolite layers. The hydraulic permeability within the Late Cretaceous rock mass penetrated by the well is due to extensive cracking in the rock.

Kopylova and Boldina [3] estimated porosity, elastic and percolation properties of this aquifer based on an analysis of tidal and barometric responses of water level. The following values were obtained:

$\begin{array}{ll}\text { specific storage } S_{s}, \mathrm{~m}^{-1} & 18.7 \times 10^{-7}, \\ \text { drained compressibility } \beta, \mathrm{Pa}^{-1} & 13.8 \times 10^{-11}, \\ \text { porosity, } \phi & 0.12, \\ \text { transmissivity } T / r_{w}^{2}, \mathrm{~s}^{-1} & 2.8 \times 10^{-5}-2.8 \times 10^{-2} .\end{array}$

Assessment of the aquifer transmissivity based on pumping tests. Postdrilling pumping test data gave the value $0.00148 \mathrm{~m}^{3} / \mathrm{s}$ for the discharge rate $Q$ with the water level decreasing by $s=17.55 \mathrm{~m}$. The aquifer transmissivity is $T=k m$, where $k$ is the percolation rate and $m$ the aquifer thickness penetrated, and it was estimated using the linear drainage model for an infinite aquifer [4, p. 93]:

$$
s=\frac{Q}{2 \pi T} \ln \frac{\lambda m}{r_{w}},
$$

where $\lambda$ is an empirical constant equal to about $0.7 ; r_{w}$ is the radius of the well where it has connection with the aquifer $\left(r_{w}=0.084 \mathrm{~m}\right)$. The value of $m$ was assumed to equal the total thickness of inflow zones in the cracked aleurolites $(100 \mathrm{~m})$.

From (1) we get $T=0.9 \times 10^{-4} \mathrm{~m}^{2} / \mathrm{s}$, from which $k=$ $0.9 \times 10^{-6} \mathrm{~m} / \mathrm{s}$ and $T / r_{w}^{2}=1 \times 10^{-2} \mathrm{~s}^{-1}$. The value of $T / r_{w}^{2}$ derived from the pumping test data thus agrees with the upper bound of the range of values estimated from the tidal and barometric responses of water level in the YuZ-5 well.

The record of the Sumatra-Andaman earthquake at the Petropavlovsk seismic station. An earthquake of $\mathbf{M}_{w}=9.3$ occurred in the area of Sumatra, Indonesia at $0 \mathrm{~h} 58 \mathrm{~min}$ on December 26, 2004, causing a disastrous tsunami and enormous human losses in Southeast Asia. The epicenter was at $3.30^{\circ} \mathrm{N}, 95.78^{\circ} \mathrm{E}$, focal depth $10 \mathrm{~km}$, the hypocentral distance to the YuZ-5 well is $8250 \mathrm{~km}$. The earthquake was recorded at the Petropavlovsk seismic station $\left(53.024^{\circ} \mathrm{N}\right.$, $158.653^{\circ} \mathrm{E}$ ) situated about $20 \mathrm{~km}$ from the well. We used the LHZ record for this study (http://www.iris.washington.edu/).

The seismic waves were recorded for more than $50 \mathrm{~min}$ at the Petropavlovsk station, from $01 \mathrm{~h} 10 \mathrm{~min}$ to around $02 \mathrm{~h}$. The vertical ground motion amplitude reached $2 \mathrm{~cm}$ (Fig. 1).

The power spectrum of ground motion displacement recorded by the LHZ channel shows maxima at periods of 17, 20, 32, and about $45 \mathrm{~s}$ (Fig. 2a). Figure 2b shows the time-frequency power spectrum for the LHZ channel.

The effects of seismic waves in water level changes. The passage of seismic waves due to that earthquake caused appreciable fluctuations in the YuZ5 water level. The table lists data from 10-min recordings of water level and atmospheric pressure for the period $18 \mathrm{~h} 00 \mathrm{~min}$, December 25 to $18 \mathrm{~h} 00 \mathrm{~min}$, December 26. Figure 1 shows water level changes set against a LHZ record of ground motion displacement at Petropavlovsk. The preprocessing of the water level record involved compensation for barometric variations and the identification of oscillations in the period range $20 \mathrm{~min}$ to $5 \mathrm{~h}$ using a high-pass filter.

The arrival of $P$ waves $(01 \mathrm{~h} 10 \mathrm{~min} 09 \mathrm{~s})$ and $S$ waves ( 01 h 20 min 49 s) was accompanied by water level fluctuations with amplitudes of at least $0.5 \mathrm{~cm}$. The $L$-wave arrival ( $01 \mathrm{~h} 32 \mathrm{~min} 57 \mathrm{~s}$ ) was accompanied by water level changes with amplitudes of at least $5 \mathrm{~cm}$. The subsequent period of about nine hours showed damped free oscillations of water level with amplitudes of $0.5-0.2 \mathrm{~cm}$. The ratio of maximum water level change amplitude to the maximum ground motion displacement during the passage of $L$ waves was at least 

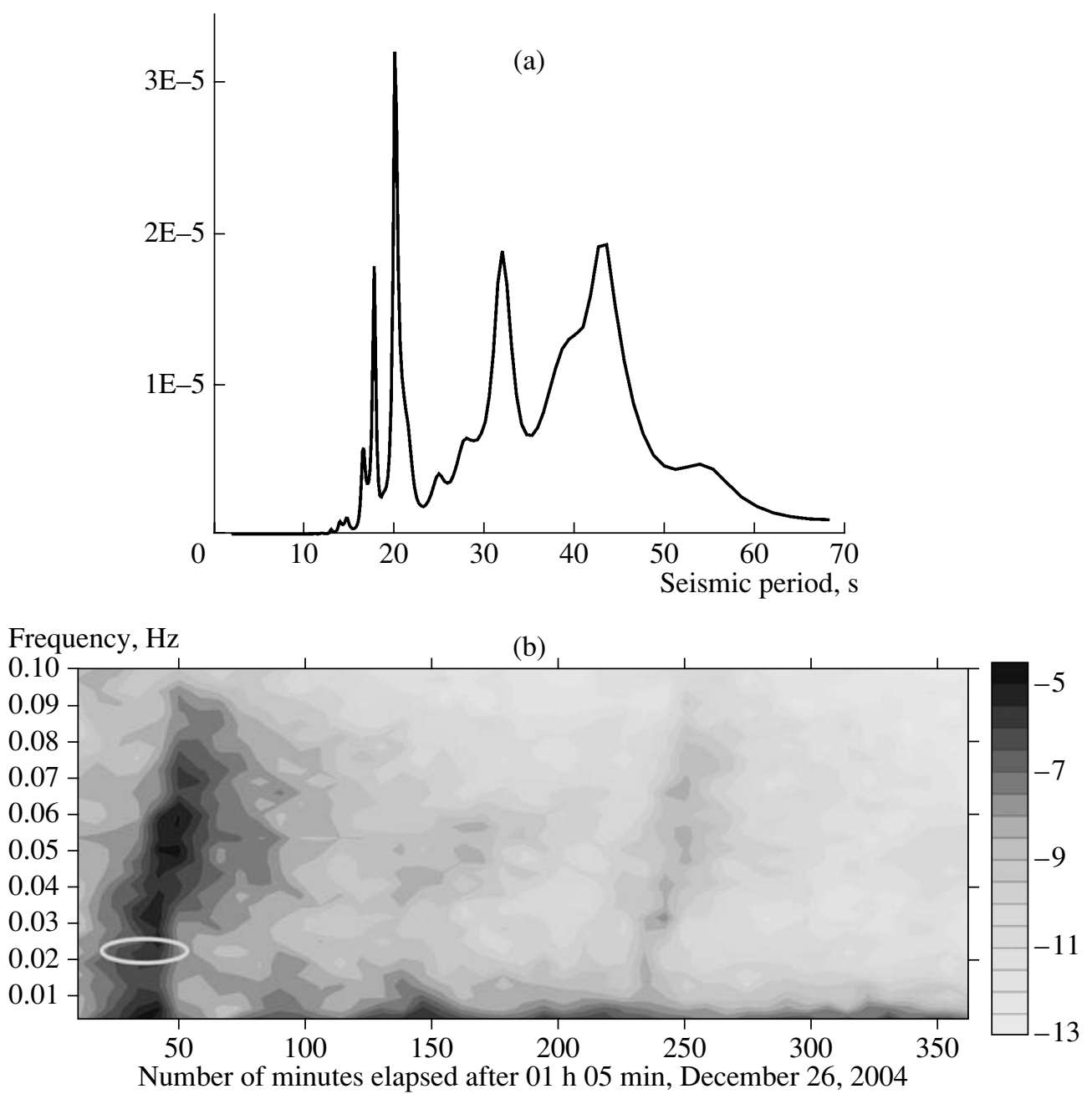

Fig. 2. Spectral analysis of displacements recorded by the LHZ channel during the December 26, 2004, Sumatra-Andaman earthquake, Petropavlovsk seismic station: (a) power spectrum computed by the Burg maximum entropy method (the record length is 60 min after $P$ onset), (b) time-dependent power spectrum in a 10-min window moving at steps of 2 min. The record length is $365 \mathrm{~min}$, consisting of $5 \mathrm{~min}$ before $P$ onset and $360 \mathrm{~min}$ after it. The ellipse encloses the frequency range corresponding to periods of $40-50 \mathrm{~s}$ in seismic surface waves.

2.5. The length of the sample period $(10 \mathrm{~min}) \mathrm{did}$ not allow us to more accurately estimate the maximum water level amplitude and the amplification factor of water level variation relative to vertical ground motion displacement.

Similar effects due to the passage of seismic surface waves on the YuZ-5 water level changes were also observed twice again: in relation to the September 25, 2003, Hokkaido earthquake $\left(\mathrm{M}_{w}=8.3, R=1670 \mathrm{~km}\right)$ and an aftershock of the Sumatra-Andaman earthquake (March 28, 2005, $\mathrm{M}_{w}=8.7, R=8200 \mathrm{~km}$ ). The maximum amplitude of water level changes was about $2 \mathrm{~cm}$ for the 2003 earthquake and $1.2 \mathrm{~cm}$ for the 2005 event. In both of these cases the maximum amplitudes were recorded during the arrival of surface waves, with the total duration of water level fluctuations being about four hours.

\section{Assessment of the Aquifer Transmissivity}

The model for water level changes in a well during the passage of seismic waves [7] is derived from the wave equation for damped oscillations of a water column in the well and in the aquifer near-percolation zone. Cooper et al. [7] showed that water level variations in a well during the passage of seismic waves may be caused by changes in aquifer pore pressure and vertical ground motion displacement (Fig. 3). The earthquake-induced response of water level in the well is controlled, not only by characteristics of the well and the aquifer penetrated, but also to a great extent, by the type and period of the seismic wave concerned. For the case of Rayleigh waves having a period equal to or greater than the well resonant frequency $\omega_{w}$, the water level changes are practically completely controlled by pore pressure changes in the aquifer $p_{0}=\rho g h_{0}$, where $\rho$ is water density, $g$ the acceleration due to gravity, and 
Recordings of water level and atmospheric pressure in the YuZ-5 well during the period $18 \mathrm{~h} 00 \mathrm{~min}$, December 25 to $18 \mathrm{~h} 00 \mathrm{~min}$, December 26, 2004, UT

\begin{tabular}{|c|c|c|c|c|c|c|c|}
\hline Date & $\begin{array}{l}\text { Time } \\
\mathrm{h}: \mathrm{min}\end{array}$ & $\begin{array}{l}\text { Water level, } \\
\quad \mathrm{cm}\end{array}$ & $\begin{array}{l}\text { Atmospheric } \\
\text { pressure, GPa }\end{array}$ & Date & $\begin{array}{l}\text { Time } \\
\mathrm{h}: \mathrm{min}\end{array}$ & $\begin{array}{l}\text { Water level, } \\
\qquad \mathrm{cm}\end{array}$ & $\begin{array}{l}\text { Atmospheric } \\
\text { pressure, GPa }\end{array}$ \\
\hline \multirow{36}{*}{$\begin{array}{c}\text { December } 25, \\
2004\end{array}$} & $18: 00$ & 262.87 & 999.3 & \multirow{43}{*}{$\begin{array}{c}\text { December 26, } \\
2004\end{array}$} & $1: 10$ & 262.74 & 1004.8 \\
\hline & $18: 10$ & 262.96 & 999.6 & & $1: 20$ & 262.30 & 1004.8 \\
\hline & $18: 20$ & 263.04 & 999.6 & & $1: 30$ & 262.45 & 1004.8 \\
\hline & $18: 30$ & 263.06 & 999.9 & & $1: 40$ & 259.51 & 1004.8 \\
\hline & $18: 40$ & 263.13 & 1000.1 & & $1: 50$ & 261.70 & 1004.8 \\
\hline & $18: 50$ & 263.17 & 1000.4 & & $2: 00$ & 263.89 & 1005.0 \\
\hline & $19: 00$ & 263.21 & 1000.7 & & $2: 10$ & 264.68 & 1005.0 \\
\hline & $19: 10$ & 263.25 & 1000.7 & & $2: 20$ & 264.70 & 1005.0 \\
\hline & $19: 20$ & 263.25 & 1001.0 & & $2: 30$ & 264.38 & 1005.3 \\
\hline & $19: 30$ & 263.36 & 1001.0 & & $2: 40$ & 264.64 & 1005.3 \\
\hline & $19: 40$ & 263.42 & 1001.0 & & $2: 50$ & 264.96 & 1005.3 \\
\hline & $19: 50$ & 263.45 & 1001.2 & & $3: 00$ & 264.93 & 1005.3 \\
\hline & $20: 00$ & 263.47 & 1001.2 & & $3: 10$ & 264.59 & 1005.3 \\
\hline & $20: 10$ & 263.49 & 1001.5 & & $3: 20$ & 264.59 & 1005.6 \\
\hline & $20: 20$ & 263.42 & 1001.8 & & $3: 30$ & 264.55 & 1005.6 \\
\hline & $20: 30$ & 263.42 & 1001.8 & & $3: 40$ & 264.87 & 1005.6 \\
\hline & $20: 40$ & 263.42 & 1002.0 & & $3: 50$ & 264.91 & 1005.6 \\
\hline & $20: 50$ & 263.45 & 1002.0 & & $4: 00$ & 264.61 & 1005.8 \\
\hline & $21: 00$ & 263.42 & 1002.3 & & $4: 10$ & 265.27 & 1005.8 \\
\hline & $21: 10$ & 263.36 & 1002.6 & & $4: 20$ & 264.64 & 1006.1 \\
\hline & $21: 20$ & 263.30 & 1002.9 & & $4: 30$ & 264.47 & 1006.1 \\
\hline & $21: 30$ & 263.25 & 1002.9 & & $4: 40$ & 264.53 & 1006.4 \\
\hline & $21: 40$ & 263.25 & 1002.9 & & $4: 50$ & 264.7 & 1006.7 \\
\hline & $21: 50$ & 263.19 & 1003.1 & & $5: 00$ & 264.38 & 1006.7 \\
\hline & $22: 00$ & 263.17 & 1003.1 & & $5: 10$ & 264.53 & 1006.7 \\
\hline & $22: 10$ & 263.06 & 1003.4 & & $5: 20$ & 264.49 & 1006.9 \\
\hline & $22: 20$ & 263.02 & 1003.4 & & $5: 30$ & 264.49 & 1007.2 \\
\hline & $22: 30$ & 262.96 & 1003.7 & & $5: 40$ & 264.13 & 1007.2 \\
\hline & $22: 40$ & 262.94 & 1003.7 & & $5: 50$ & 263.98 & 1007.2 \\
\hline & $22: 50$ & 262.83 & 1003.9 & & $6: 00$ & 264.17 & 1007.5 \\
\hline & $23: 00$ & 262.79 & 1004.2 & & $6: 10$ & 264.08 & 1007.5 \\
\hline & $23: 10$ & 262.77 & 1004.2 & & $6: 20$ & 263.93 & 1007.7 \\
\hline & $23: 20$ & 262.72 & 1004.2 & & $6: 30$ & 263.74 & 1007.7 \\
\hline & $23: 30$ & 262.70 & 1004.2 & & $6: 40$ & 263.74 & 1007.7 \\
\hline & $23: 40$ & 262.70 & 1004.5 & & $6: 50$ & 263.57 & 1007.7 \\
\hline & $23: 50$ & 262.66 & 1004.5 & & $7: 00$ & 263.28 & 1008.0 \\
\hline \multirow{7}{*}{$\begin{array}{c}\text { December } 26, \\
2004\end{array}$} & 00:00 & 262.6 & 1004.8 & & $7: 10$ & 263.45 & 1008.0 \\
\hline & $00: 10$ & 262.64 & 1004.5 & & $7: 20$ & 263.32 & 1008.0 \\
\hline & $00: 20$ & 262.66 & 1004.5 & & $7: 30$ & 263.02 & 1008.6 \\
\hline & $00: 30$ & 262.68 & 1004.5 & & $7: 40$ & 262.64 & 1008.6 \\
\hline & $00: 40$ & 262.72 & 1004.5 & & $7: 50$ & 262.66 & 1008.6 \\
\hline & $00: 50$ & 262.72 & 1004.5 & & $8: 00$ & 262.38 & 1008.8 \\
\hline & 1:00 & 262.72 & 1004.8 & & $8: 10$ & 262.3 & 1008.8 \\
\hline
\end{tabular}


Table. (Contd.)

\begin{tabular}{|c|c|c|c|c|c|c|c|}
\hline Date & $\begin{array}{l}\text { Time } \\
\mathrm{h}: \min \end{array}$ & $\begin{array}{c}\text { Water level, } \\
\mathrm{cm}\end{array}$ & $\begin{array}{l}\text { Atmospheric } \\
\text { pressure, GPa }\end{array}$ & Date & $\begin{array}{l}\text { Time } \\
\mathrm{h}: \min \end{array}$ & $\begin{array}{l}\text { Water level, } \\
\mathrm{cm}\end{array}$ & $\begin{array}{l}\text { Atmospheric } \\
\text { pressure, GPa }\end{array}$ \\
\hline $\begin{array}{c}\text { December } 26, \\
2004\end{array}$ & $\begin{array}{r}8: 20 \\
8: 30 \\
8: 40 \\
8: 50 \\
9: 00 \\
9: 10 \\
9: 20 \\
9: 30 \\
9: 40 \\
9: 50 \\
10: 00 \\
10: 10 \\
10: 20 \\
10: 30 \\
10: 40 \\
10: 50 \\
11: 00 \\
11: 10 \\
11: 20 \\
11: 30 \\
11: 40 \\
11: 50 \\
12: 00 \\
12: 10 \\
12: 20 \\
12: 30 \\
12: 40 \\
12: 50 \\
13: 00\end{array}$ & $\begin{array}{l}261.91 \\
261.89 \\
261.60 \\
261.26 \\
261.09 \\
261.04 \\
260.72 \\
260.43 \\
260.19 \\
259.96 \\
259.58 \\
259.43 \\
259.26 \\
259.15 \\
258.98 \\
258.64 \\
258.36 \\
258.28 \\
257.9 \\
257.81 \\
257.6 \\
257.45 \\
257.24 \\
257.19 \\
256.96 \\
256.81 \\
256.68 \\
256.66 \\
256.6\end{array}$ & $\begin{array}{l}1008.8 \\
1008.8 \\
1009.1 \\
1009.1 \\
1009.4 \\
1009.4 \\
1009.4 \\
1009.6 \\
1009.4 \\
1009.4 \\
1009.6 \\
1009.6 \\
1009.6 \\
1009.6 \\
1009.6 \\
1009.9 \\
1009.9 \\
1009.9 \\
1009.9 \\
1010.2 \\
1010.2 \\
1010.2 \\
1010.2 \\
1010.2 \\
1010.5 \\
1010.7 \\
1010.7 \\
1010.7 \\
1010.7\end{array}$ & $\begin{array}{c}\text { December 26, } \\
2004\end{array}$ & $\begin{array}{l}13: 10 \\
13: 20 \\
13: 30 \\
13: 40 \\
13: 50 \\
14: 00 \\
14: 10 \\
14: 20 \\
14: 30 \\
14: 50 \\
15: 00 \\
15: 10 \\
15: 20 \\
15: 30 \\
15: 40 \\
15: 50 \\
16: 00 \\
16: 10 \\
16: 20 \\
16: 30 \\
16: 40 \\
16: 50 \\
17: 00 \\
17: 10 \\
17: 20 \\
17: 30 \\
17: 40 \\
17: 50 \\
18: 00\end{array}$ & $\begin{array}{l}256.45 \\
256.34 \\
256.34 \\
256.41 \\
256.41 \\
256.37 \\
256.43 \\
256.41 \\
256.47 \\
256.56 \\
256.64 \\
256.66 \\
256.64 \\
256.68 \\
256.79 \\
256.88 \\
257.11 \\
257.28 \\
257.45 \\
257.51 \\
257.68 \\
257.88 \\
258.00 \\
258.17 \\
258.34 \\
258.49 \\
258.62 \\
258.75 \\
259.02\end{array}$ & $\begin{array}{l}1010.7 \\
1010.7 \\
1011 \\
1010.7 \\
1010.7 \\
1010.7 \\
1010.7 \\
1010.7 \\
1010.7 \\
1010.7 \\
1010.7 \\
1011.0 \\
1011.0 \\
1011.0 \\
1011.0 \\
1011.3 \\
1011.3 \\
1011.3 \\
1011.3 \\
1011.3 \\
1011.3 \\
1011.3 \\
1011.3 \\
1011.3 \\
1011.3 \\
1011.5 \\
1011.5 \\
1011.5 \\
1011.5\end{array}$ \\
\hline
\end{tabular}

$h_{0}$ the amplitude of head pressure change due to the strain in the water-bearing rocks arising during the passage of seismic waves.

The resonant frequency $\omega_{w}$ is mainly dependent on the effective height of water column in the well $H_{e}=$ $H+3 d / 8$, where $H$ is the water column height in the encased well and $d$ the water column height in the region of the screened aquifer. We have $H=310 \mathrm{~m}$ and $d=490 \mathrm{~m}$ for the YuZ-5 well, and the effective water column is $494 \mathrm{~m}$ high.

The resonant frequency of the well is found as $\omega_{w} \approx$ $\left(g / H_{e}\right)^{1 / 2}$. From this one can estimate the periods of seismic waves that can produce resonance by amplifying harmonic variations of pore pressure in the well at high enough values of transmissivity: $\tau \geq 2 \pi / \omega_{w}$. Taking the case of the YuZ-5 well, resonant water level variations can arise during the passage of waves with periods about $40 \mathrm{~s}$ or greater. Figure $2 \mathrm{~b}$ shows the seismic frequency range (enclosed in the ellipse) that can have produced a resonant amplification of YuZ-5 water level variations due to the December 26, 2004, earthquake.

The amplification of water level variations in the well relative to head pressure changes in the aquifer for resonant frequencies is expressed by (after [7])

$$
\begin{aligned}
A=x_{0} / h_{0} & =\left[\left(1-\frac{\pi r_{w}^{2}}{T \tau} \operatorname{Kei}_{w}-\frac{4 \pi^{2} H_{e}}{\tau^{2} g}\right)^{2}\right. \\
& \left.+\left(\frac{\pi r_{w}^{2}}{T \tau} \operatorname{Ker}_{w}\right)^{2}\right]^{-1 / 2},
\end{aligned}
$$


(a)

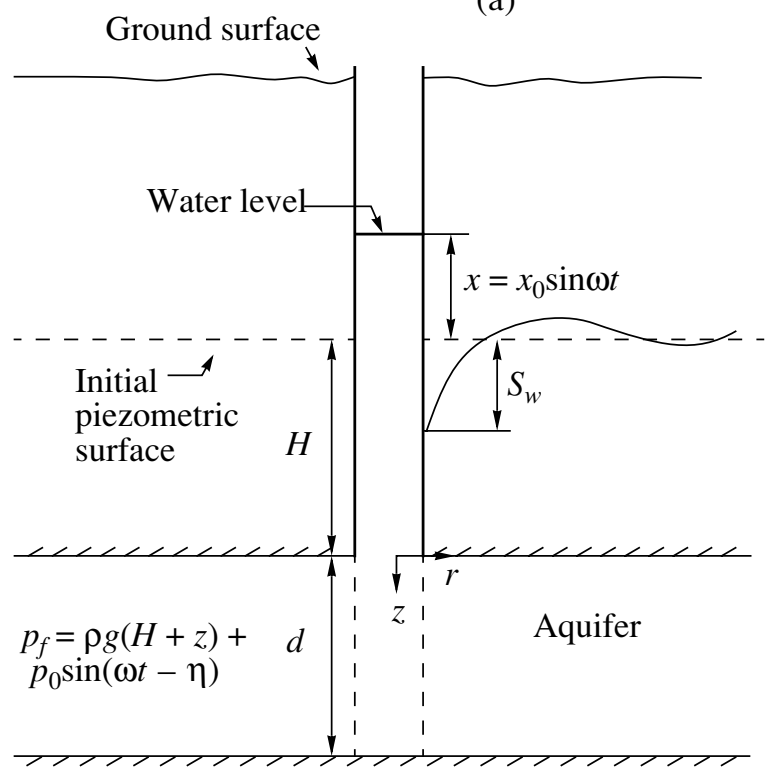

(b)

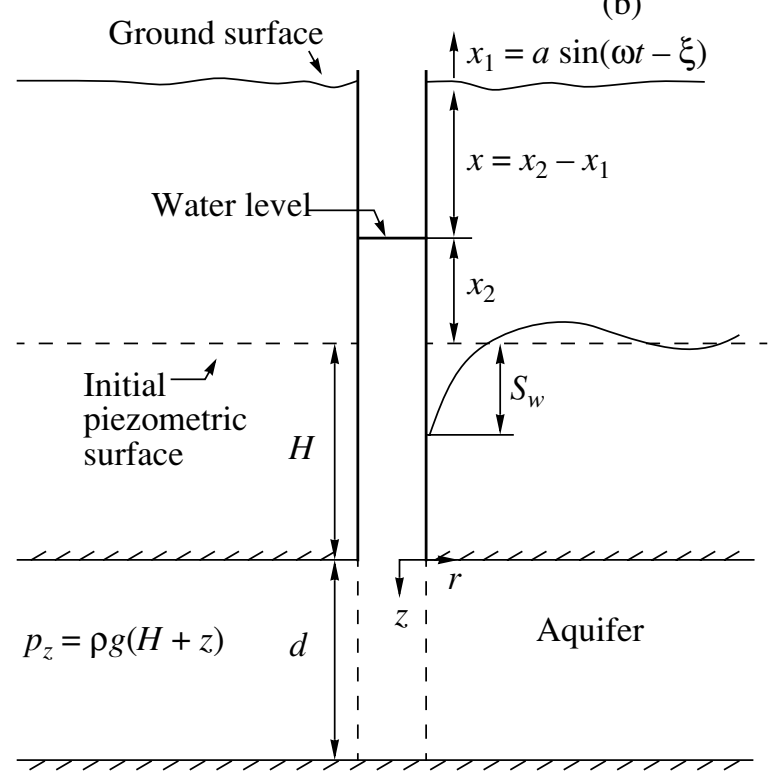

Fig. 3. Diagrammatic representation of how the response of water level in a well is generated: (a) response to harmonic variations in aquifer pore pressure, (b) response to vertical displacements in the well-aquifer system during the passage of seismic waves. $H$ the height of the water column in an encased well, $d$ aquifer thickness (the length of the screened interval along the well), $z$ depth below the casing, $r$ horizontal distance from the center of the well, $s_{w}$ change in aquifer head pressure, $x$ the change in water level for harmonic oscillations of amplitude $x_{0}$; $\omega$ is the angular frequency of seismic wave, $t$ the time; $p_{f}=\rho g(H+z)+p_{0} \sin (\omega t-\eta)$ is an expression for aquifer pore pressure variations when the pressure varies harmonically with amplitude $p_{0} ; p_{z}$ is the hydrostatic component of pore pressure, $\eta$ the phase shift between seismic wave displacement and pore pressure variation, $x_{1}$ is harmonic displacement of ground surface of amplitude $a ; x_{2}$ is the movement of water column due to vertical displacements of ground surface, $\xi$ is the phase shift between seismic wave displacement and vertical displacement of ground surface [6].

where $x_{0}$ is the amplitude of water level change, $h_{0}$ that of head pressure change, $\alpha_{w}=r_{w}(\omega S / T)^{1 / 2}$ is a dimensionless function of frequency expressed in terms of aquifer parameters and the well geometrical parameters: $r_{w}$, the radius of the well where it has connection with the aquifer, $S$ the storage coefficient of the aquifer, $S=S_{s} m$ the aquifer transmissivity, $\operatorname{Ker}_{w}$ and $\operatorname{Kei}_{w}$ are the real and imaginary parts of a Kelvin function of zero order.

The amplification of water level variations relative to the vertical ground motion displacement $A^{\prime}$ is expressed by

$$
A^{\prime}=x_{0} / a=\frac{4 \pi^{2} H_{e}}{\tau^{2} g} A,
$$

where $a$ is the amplitude of ground motion displacement.

The $A / A^{\prime}$ ratio for YuZ-5 at resonant frequencies $\tau \geq$ $44.6 \mathrm{~s}$ is practically unity $\left(A / A^{\prime} \approx 1\right)$. Assuming $A^{\prime}=A \geq$ 2.5 , one can use (2) to assess the transmissivity of the aquifer penetrated by the YuZ-5 well. To do this, we calculated the amplification of water level variations relative to the head pressure change in the aquifer, $A=x_{0} / h_{0}$, as a function of seismic period $\tau$ (Fig. 4a). It was assumed that the aquifer transmissivity can vary within a range of five orders of magnitude, while the storage coefficient $S$ is constant, and is equal to $18.7 \times 10^{-5}$.
The modeling results show that water level variations could be amplified relative to the head pressure change when the value of $T / r_{w}^{2}$ was at least $1 \mathrm{~s}^{-1}$. A previous analysis of tidal and barometric responses of YuZ-5 water level gave $2.8 \times 10^{-2} \mathrm{~s}^{-1}$ as the most probable value of $T / r_{w}^{2}$ [3]. Aquifer transmissivity as estimated from pumping test data also gave a comparable value, $T / r_{w}^{2}=1 \times 10^{-2} \mathrm{~s}^{-1}$.

One analogue of observed water level variations during the passage of seismic waves (Fig. 1) is supplied by damped oscillations of water level due to an instantaneous injection/withdrawal of well water. As a rule, high frequency oscillations of water level during the first phases of recovery following an instantaneous water injection arise in wells that penetrate highly permeable aquifers. Such oscillations can also be explained by the inertia and capacity of the well concerned [5,9].

The solution for such water level changes in an experimental well derived from the wave equation for damped oscillations has the form [9]

$$
\begin{gathered}
h=h_{0} \exp \left(-\omega_{w} \kappa t\right) \cos \left(\omega_{w} \sqrt{1-\kappa^{2}} t\right), \\
\kappa=-\frac{r_{c}^{2}}{8 T} \omega_{w} \ln \left(0.79 r_{w}^{2} \frac{S}{T} \omega_{w}\right),
\end{gathered}
$$


Amplitude ratio $\left(x_{0} / h_{0}\right)$

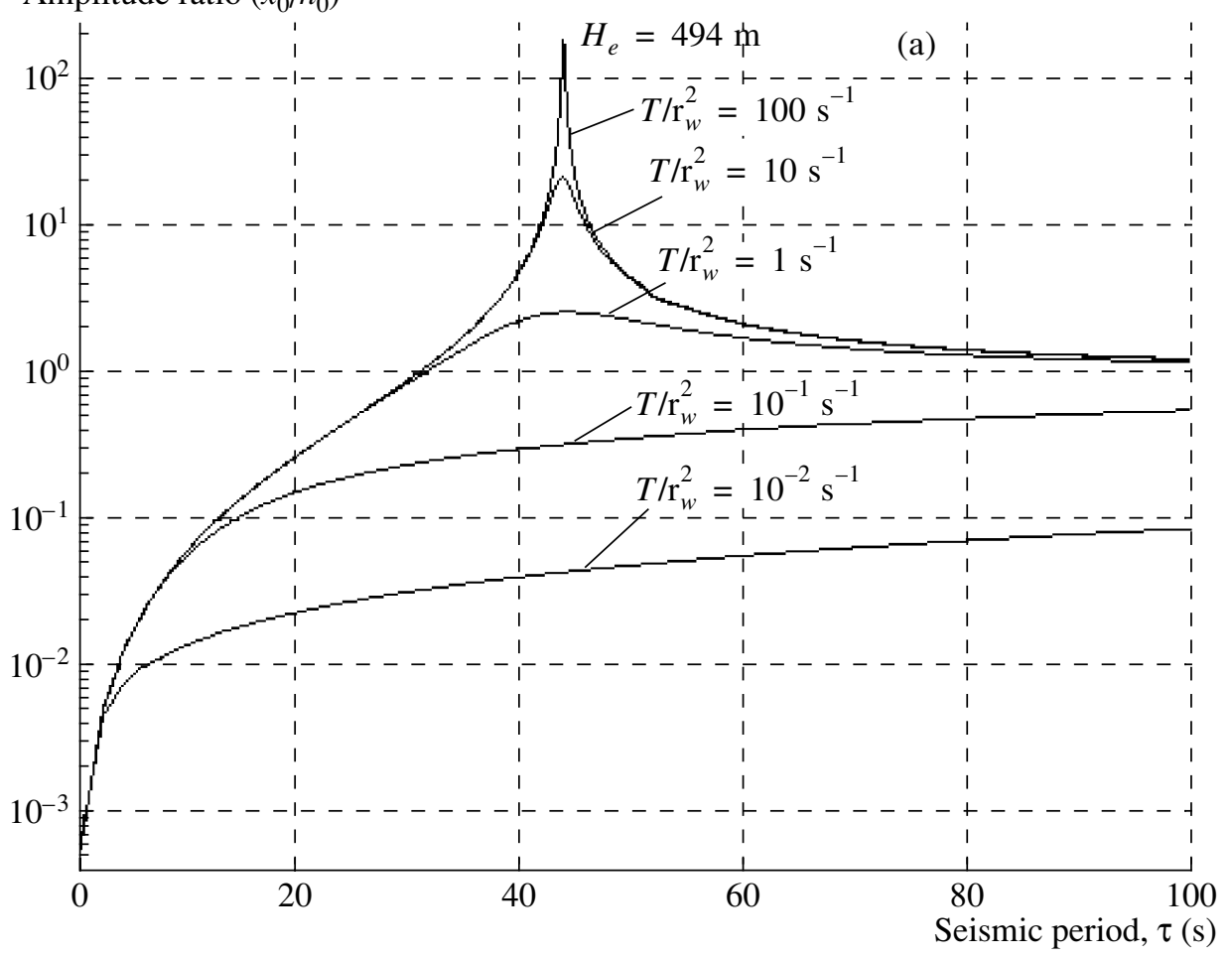

Amplitude of oscillation, $\mathrm{m}$

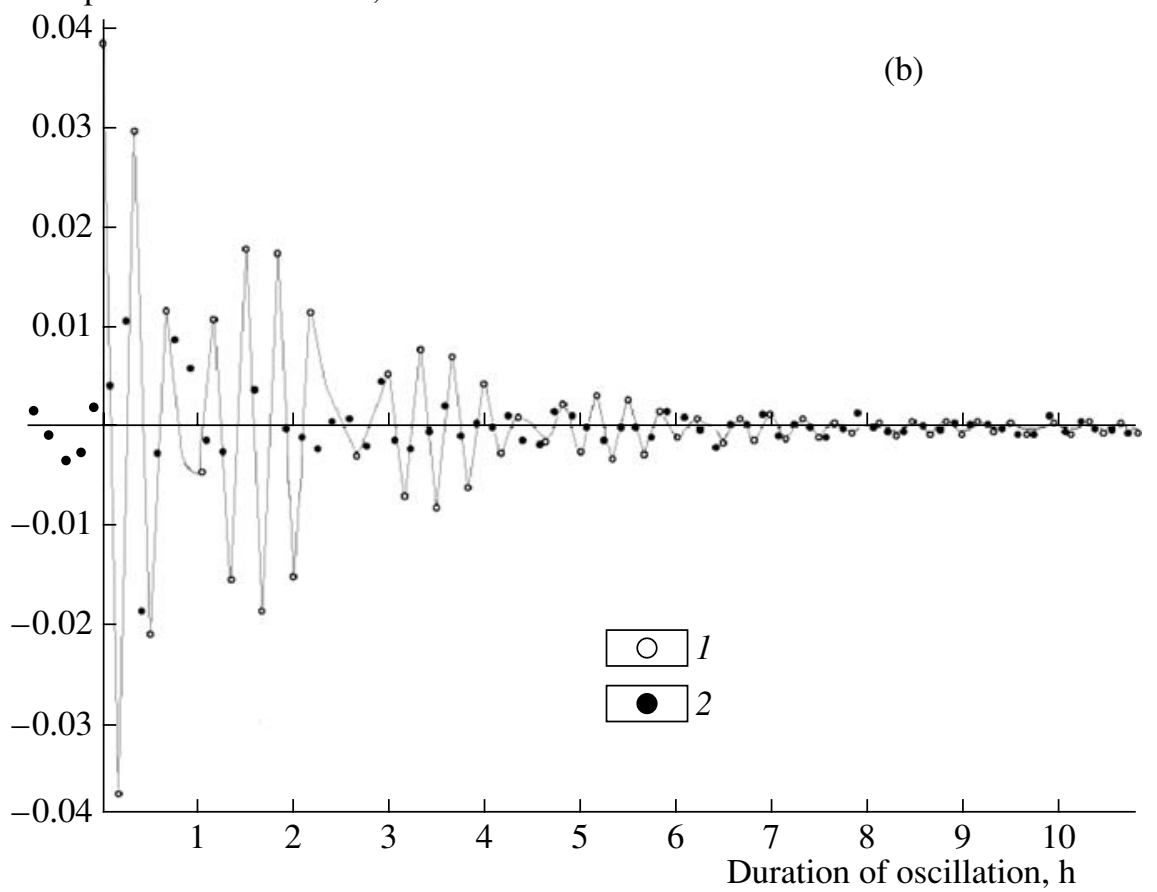

Fig. 4. Modeling the oscillatory behavior of the water level in the YuZ-5 well in order to estimate the aquifer transmissivity: (a) change in the amplitude ratio between water level variation and aquifer head pressure changes $x_{0} / h_{0}$ as a function of $T / r_{w}^{2}$ (a parameter of the well-aquifer system) and seismic period $\tau$, (b) comparison between 10-min water level variations in the YuZ-5 well and theoretical water level variations given by (4), (5). (1) Theoretical water level for initial amplitude $h_{0}=4.2 \mathrm{~cm}$, transmissivity $T=5 \mathrm{~m}^{2} / \mathrm{s}$, water yield $S=18.7 \times 10^{-5}$; (2) observed water level left after the compensation for atmospheric pressure variations and high-pass filtering in a 1-h window. The zero point of the time axis corresponds to the seismic onset at $01 \mathrm{~h} 10 \mathrm{~min}$. 


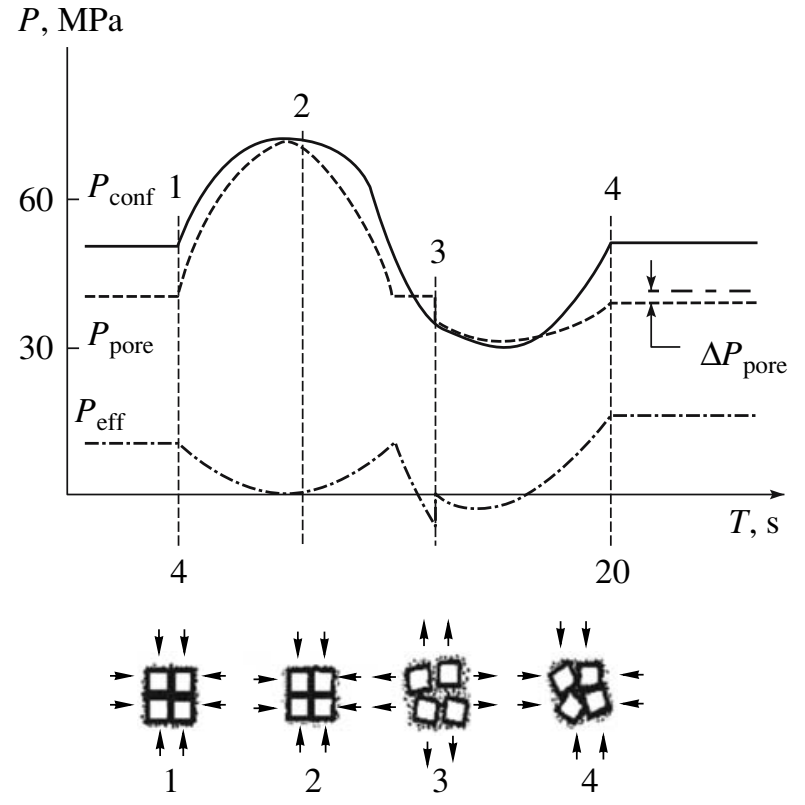

Fig. 5. Change in confining pressure $\left(\mathrm{P}_{\text {conf }}\right)$, pore pressure $\left(\mathrm{P}_{\text {pore }}\right)$, and effective pressure $\left(\mathrm{P}_{\text {eff }}\right)$ during the passage of seismic waves through rock [5]: (1) initial state of the water-rock system, (2) phase of increased confining and pore pressure, and specimen compression, (3) phase of lower confining pressure, specimen failure under pore pressure, (4) compression phase, mechanical deformation of specimen, $\Delta \mathrm{P}_{\text {pore }}$ is the drop in pore pressure due to disturbances in specimen structure induced by seismic vibration.

where $h$ is water level change, $h_{0}$ the initial (instantaneous) change in water level, and $t$ the time.

Comparison of theoretical water level variations as given by (4), (5) with those actually observed in the well over time yields an estimate of aquifer transmissivity $T$ for an assigned water yield $S$ (Fig. 4b). The optimal approximation of 10-min water level observations during the Sumatra-Andaman earthquake to the theoretical curve, (optimal, that is, as concerns the character of amplitude decay and the duration of water level variations) was obtained for the initial amplitude $h_{0}=$ $4.2 \mathrm{~cm}$, transmissivity $T=5 \mathrm{~m}^{2} / \mathrm{s}$, and storage coefficient $S=18.7 \times 10^{-5}$. From this it follows that an oscillatory behavior of water level variations in the YuZ-5 well following an instantaneous water injection can only arise, when the transmissivity $T / r_{w}^{2}$ is at least $7.1 \times 10^{2} \mathrm{~s}^{-1}$.

We wish to point out an important difference between the mechanism responsible for the generation of water level oscillations due to an instantaneous well test and during the passage of seismic waves. In the former case, the well-aquifer system is excited by an amount of water injected into or withdrawn from the well. Low frequency seismic waves can give rise to water level oscillations by amplifying pore pressure variations in the well caused by deformation in the water-bearing rocks, as well as by vertical ground surface displacements (Fig. 3). At the same time, comparison of transmissivity values obtained according to the models of [7] and [9] with those obtained from pumping test data show that if the YuZ-5 water level oscillations are to be accounted for one should invoke the hypothesis of considerably improved transmissivity in the aquifer rocks.

\section{DISCUSSION OF RESULTS}

Forced and free oscillations of water level in the YuZ-5 well are only observed during very large and distant earthquakes $(\mathrm{M}=8.3-9.3, R=1670-8250 \mathrm{~km})$, which generate surface waves of periods as long as several tens of seconds, and can produce a resonant effect of amplified harmonic oscillations of pore pressure in the well-aquifer system (Fig. 3a). Such water level oscillations have not been recorded in the YuZ-5 well when local earthquakes of magnitudes between less than 5.0 and 7.9 occurred. This is explained by the rather poor generation of long period surface waves by local earthquakes at hypocentral distances of only a few hundreds of kilometers. Recording once in $10 \mathrm{~min}$ does not allow accurate estimation of the water level amplitude and period during the Sumatra-Andaman earthquake and similar seismic events. One should be able to record water level at least once every $1-10 \mathrm{~s}$. This drawback in the recording system prevents us at present from constructing a reliable quantitative relationship connecting the generation of water level oscillations in the YuZ-5 well and the character of seismic waves.

A comparison of aquifer transmissivity based on tidal and barometric responses of water level and on pumping test data with those roughly assessed from the amplitude of water level change during the passage of seismic waves (Fig. 4a) and from the theoretical plot of time behavior (Fig. 4b) shows that the two are significantly different. The model of [7], which describes the oscillatory behavior of water level due to the amplification of pore pressure variations in the well during the passage of seismic surface waves, yielded a transmissivity about two orders greater $\left(T / r_{w}^{2} \geq 1 \mathrm{~s}^{-1}\right)$.

This difference in aquifer transmissivity induced by comparatively slow variations in pore pressure due to tidal and barometric excitation, as well as to pumping test (a few hours to a few days) and by seismic excitation (a few seconds to a few tens of seconds) can be explained by increased permeability and improved percolation of the aquifer rocks during the passage of surface waves excited by large teleseismic events.

Figure 5 shows results from physical modeling of the effects of seismic vibration on the permeability of water-saturated basalt, gabbro, and limestone specimens [6]. The quantities recorded in this experiment include confining pressure to model a seismic wave $\left(\mathrm{P}_{\text {conf }}\right)$; pore pressure in the specimen $\left(\mathrm{P}_{\text {pore }}\right)$, and effective pressure in the rock framework $\left(\mathrm{P}_{\mathrm{eff}}\right)$. The oscilla- 
tions had a frequency of $0.065 \mathrm{~Hz}$, and the excitation lasted $0.25-22 \mathrm{~h}$.

It was found that, when the confining pressure is below the pore pressure $\left(\mathrm{P}_{\text {conf }}<\mathrm{P}_{\text {pore }}\right)$, the specimens had permeabilities after the seismic excitation that were 1.2-3.7 times those before it, owing to the disturbed structure of the specimens. During the low phase of confining pressure, the pore pressure $\mathrm{P}_{\text {pore }}$ had a delayed drop in value. This caused a sharp increase in the effective pressure $\mathrm{P}_{\text {eff }}$ in the rock framework, exceeding its strength (phase 3 in Fig. 5). The result was hydraulic fracturing that disturbed the original specimen structure. This mechanism provides a qualitative explanation of increased permeability in water-saturated rock, hence improved percolation in aquifer rocks during the passage of seismic waves.

Nevertheless, our last conclusion regarding the considerably improved percolation in aquifer rocks during the passage of low frequency seismic waves needs to be subjected to experimental testing at the YuZ-5 well itself. To do this, it would be necessary to record the water level at least once every 1-10 s and to more accurately determine the transmissivity of the aquifer by instantaneous injection of water during seismically quiet times and after the occurrence of a large earthquake.

\section{CONCLUSIONS}

(1) Forced and free water level oscillations were recorded in the YuZ-5 well as a result of seismic waves coming from the December 26, 2004, Sumatra-Andaman earthquake $\left(\mathrm{M}_{w}=9.3, R=8250 \mathrm{~km}\right)$. The greatest recorded amplitude of water level variation was at least $5 \mathrm{~cm}$, which was observed during the arrival of seismic surface waves with typical periods of 20 to $50 \mathrm{~s}$. The water level variations were amplified by a ratio of at least 2.5 relative to vertical ground motion displacement. The earthquake-induced forced and free oscillations of water level lasted a total of about ten hours.

(2) Theoretical estimates for the generation of damped water level oscillations of period $\tau \approx 40 \mathrm{~s}$ in the YuZ-5 well due to the resonant amplification of pore pressure variations in the well-aquifer system as excited by seismic waves and by instantaneous injections of water (following the models of [7] and [9]) showed that such variations in water level can only arise when $T / r_{w}^{2}$ is at least $1 \mathrm{~s}^{-1}$. This value is two orders as great as that obtained from tidal and barometric responses of water level and from pumping tests $\left(T / r_{w}^{2} \leq 1.0-2.8 \times 10^{-2} \mathrm{~s}^{-1}\right)$.

(3) A hypothesis is thus suggested that explains the temporary improvement in the percolation of aquifer rocks during the passage of seismic surface waves as being due to disturbances in the structure of crack-pore space and a dramatic increase in the permeability. This hypothesis can be tested if the level-measuring system for the YuZ-5 well is improved.

\section{ACKNOWLEDGMENTS}

We thank Dr. Sci. (Geol.-Mineral.) A.V. Kiryukhin for a helpful discussion of this paper, and colleagues at the Kamchatka Branch, RAS Geophysical Service D.V. Droznin, N.P. Kozyreva, and E.A. Pantyukhin for help in processing the seismic record of the December 26, 2004, earthquake.

\section{REFERENCES}

1. Katalog predvestnikov zemletryasenii. Gidrogeodinamicheskie predvestniki (A Catalog of Earthquake Precursors: Hydrogeodynamic Precursors), Moscow: IFZ AN SSSR, 1983.

2. Kopylova, G.N., Lyubushin, A.A., Jr., Malugin, V.A., et al., Hydrodynamic Observations at the Petropavlovsk Site, Kamchatka, Vulkanol. Seismol., 2000, no. 4, pp. 69-79.

3. Kopylova, G.N. and Boldina, S.V., Evaluation of Pore Elastic Parameters for an Aquifer: Water Level Observations at the YuZ-5 Well, Kamchatka, Vulkanol. Seismol., 2006, no. 2, pp. 17-28.

4. Osnovy gidrogeologii. Gidrogeodinamika (Principles of Hydrogeology. Hydrogeodynamics), Novosibirsk: Nauka, 1983.

5. Sindalovskii, L.N., Spravochnik analiticheskikh reshenii dlya interpretatsii opytno-fil'tratsionnykh oprobovanii (A Handbook of Analytical Solutions for Interpretation of Percolation Tests), St. Petersburg: St. Petersburg University, 2006.

6. Shmonov, V.M., Vitovtova, V.M., and Zharikov, A.V., The Influence of Seismic Vibration on Rock Permeability in Connection with the Disposal of Nuclear Waste, in: Flyuidnaya pronitsaemost' porod zemnoi kory (Fluid Permeability of Crustal Rocks), Moscow: Nauchnyi Mir, 2002, pp. 155-161.

7. Cooper, H.H., Bredehoeft, J.D., Papadopulos, I.S., et al., The Response of Well-Aquifer System to Seismic Waves, J. Geophys. Res., 1965, vol. 70, pp. 3915-3926.

8. Sterling, A. and Smets, E., Study of Earth Tides, Earthquakes and Terrestrial Spectroscopy by Analysis of the Level Fluctuations in Borehole at Haibaart (Belgium), Geophys. J. Roy. Astr. Soc., 1971, vol. 23, no. 2, pp. 225242.

9. Van der Kamp, G., Determining Aquifer Transmissivity by Means of Well Response Tests: The Underdamped Case, Water Resources Res., 1976, vol. 12, no. 1, pp. 7177. 